\title{
Pregnant women's knowledge of weight, weight gain, complications of obesity and weight management strategies in pregnancy
}

\author{
Alexis Shub ${ }^{1 *}$, Emily Y-S Huning ${ }^{1}$, Karen J Campbell ${ }^{2}$ and Elizabeth A McCarthy ${ }^{1}$
}

\begin{abstract}
Background: Obesity is increasingly common in the obstetric population. Maternal obesity and excess gestational weight gain (GWG) are associated with increased perinatal risk. There is limited published data demonstrating the level of pregnant women's knowledge regarding these problems, their consequences and management strategies. We aimed to assess the level of knowledge of pregnant women regarding: (i) their own weight and body mass index (BMI) category, (ii) awareness of guidelines for GWG, (iii) concordance of women's own expectations with guidelines, (iv) knowledge of complications associated with excess GWG, and (v) knowledge of safe weight management strategies in pregnancy.
\end{abstract}

Methods: 364 pregnant women from a single center university hospital antenatal clinic were interviewed by an obstetric registrar. The women in this convenience sample were asked to identify their weight category, their understanding of the complications of obesity and excessive GWG in pregnancy and safe and/or effective weight management strategies in pregnancy.

Results: Nearly half (47.8\%) of the study population were overweight or obese. $74 \%$ of obese women underestimated their BMI category. $64 \%$ of obese women and $40 \%$ of overweight women overestimated their recommended GWG. Women's knowledge of the specific risks associated with excess GWG or maternal obesity was poor. Women also reported many incorrect beliefs about safe weight management in pregnancy.

Conclusions: Many pregnant women have poor knowledge about obesity, GWG, their consequences and management strategies. Bridging this knowledge gap is an important step towards improving perinatal outcomes for all pregnant women, especially those who enter pregnancy overweight or obese.

Keywords: Overweight, Obesity, Pregnancy, Body mass index, Weight gain, Knowledge, Complications

\section{Background}

Overweight and obesity are common problems with an increasing worldwide incidence [1]. Recent Australian data showed that $50 \%$ of pregnant women were overweight or obese and in the United States $36 \%$ of women were obese $[2,3]$.

Maternal obesity and excessive gestational weight gain (GWG) have well recognized associations with preeclampsia, gestational diabetes mellitus (GDM), instrumental or operative delivery, failed induction, fetal macrosomia,

\footnotetext{
*Correspondence: ashub@unimelb.edu.au

'Department of Obstetrics and Gynaecology, University of Melbourne, Perinatal Centre, 3rd Floor, Mercy Hospital for Women, 163 Studley Road, Heidelberg, Victoria, 3078, Australia

Full list of author information is available at the end of the article
}

neonatal hypoglycaemia, perinatal mortality and infant and childhood obesity [4-7]. In addition, maternal obesity is the single most common modifiable factor in stillbirth in the developed world [8].

There is limited published data assessing the relationship between a woman's actual and perceived Body Mass Index (BMI) in pregnancy, and the effect this has on GWG. It has been demonstrated that overweight and obese pregnant women are less likely than women of normal weight to correctly assess their own BMI [9], and that overweight women who underestimate their BMI are more likely to gain excess weight in pregnancy [10].

In addition to assessing pregnant women's accuracy in estimating their own BMI, this study aimed to describe 
pregnant women's awareness of GWG guidelines; knowledge of safe/effective methods of weight management in pregnancy and; awareness of complications of obesity and excess GWG in pregnancy. We aimed to determine if women's knowledge was influenced by factors including age, antenatal care provider or education from a dietitian. A greater understanding of the expectations and levels of knowledge of pregnant women regarding these factors will allow us to better design programs to educate and assist women in achieving appropriate GWG.

\section{Methods}

The study was approved by the Mercy Hospital for Women Human Research Ethics Committee. Participants were recruited by convenience sampling in the waiting room of an urban, university affiliated, tertiary maternity hospital between June and August 2010. The hospital has approximately 5000 deliveries per year with a wide mix of ethnicities represented. The sample size for this unfunded, descriptive study was limited by pragmatic considerations. After 2 months recruiting, 364 women had consented to be involved in the study.

Informed consent was obtained from each participant prior to commencement of the interview. Women were excluded from the study if they had a multiple pregnancy, diabetes mellitus prior to pregnancy or if they were non-English speaking without an appropriately qualified interpreter present. Figure 1 shows the flow of participants through the study. Twenty five women were ineligible to participate. Eleven women were underweight and due to the small numbers were excluded from further analysis.

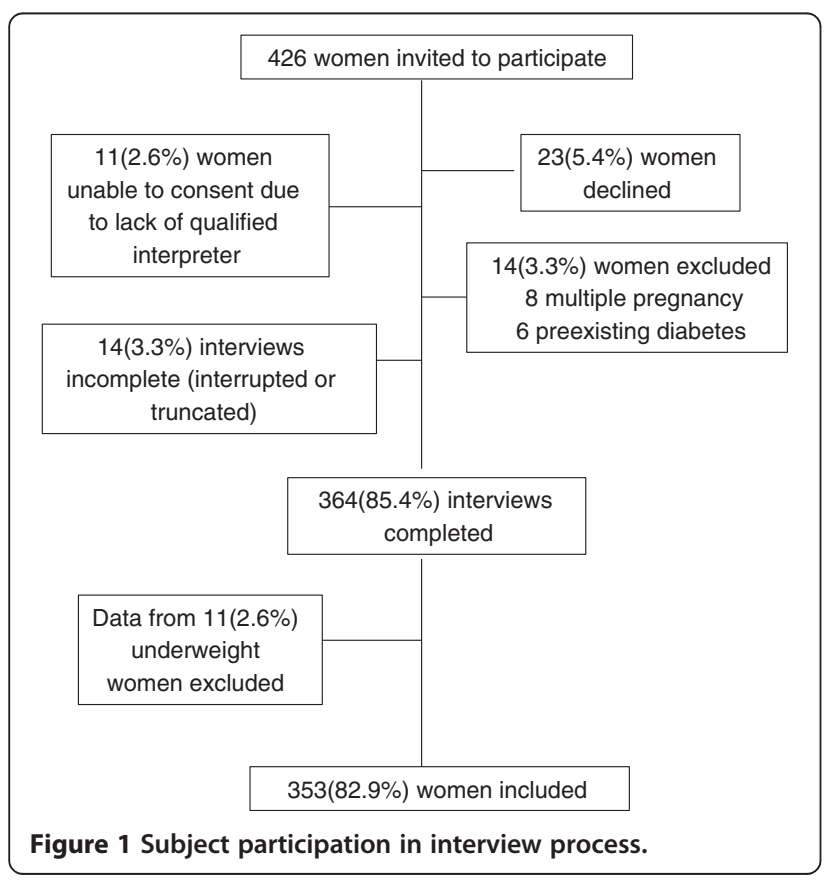

Pregnancy weight and height were self-reported from early pregnancy, except where women did not know their weight or height and thus were weighed or measured by the researcher $(\mathrm{EH})[11]$.

A 40 item questionnaire was developed by 2 of the authors (EH and AS) in conjunction with other obstetricians, midwives and dietitians and refined after piloting. Women were asked simple demographic information, then to identify themselves as being underweight, normal weight, overweight or very overweight. They were asked what they thought was the best pregnancy weight gain was for themselves. They were then asked if they believed that obesity in pregnancy or excess GWG were associated with problems for mother or for baby, and women who had replied positively were asked to list those problems. They were also asked whether a number of dietary practices were safe ways to manage weight gain in pregnancy (see Additional file 1).

The interviewer $(\mathrm{EH})$, an obstetric registrar not involved in providing antenatal care to study participants at the time of the study, transcribed participants' responses contemporaneously with pen and paper and later entered paper based form responses into a spreadsheet. The Institute of Medicine (IOM) guidelines for weight gain in pregnancy [12] and the Australian guide to healthy eating [13] formed the basis of "expert opinion" against which participant opinions were judged to be correct or incorrect. A one-week test-retest assessment of question reliability in a separate sample of 20 women demonstrated $100 \%$ agreement for 23 of 40 questions with no question having less than $65 \%$ agreement between test and re-test. Of 15 items for which kappa could be calculated, the median was 0.634 with interquartile range 0.443 to 0.798 , confirming acceptable reliability.

After completing the questionnaire, women were offered information on their own BMI and the guidelines for weight gain in pregnancy, and advised to discuss their personal care further with their obstetric care provider.

Statistical analysis was performed using PASW Statistics 18 (IBM, Armonk, New York). Normally distributed continuous data was described as means and standard deviations. Categorical data was described using proportions and compared using Chi squared tests. $\mathrm{p}<0.05$ was considered significant.

\section{Results}

Of the 353 participants, 179 (50.7\%) women were classified by BMI as being normal weight (BMI 20-24.9 $\mathrm{kg} / \mathrm{m}^{2)}, 99(28.0 \%)$ were classified as overweight (BMI $\left.25-29.9 \mathrm{~kg} / \mathrm{m}^{2}\right)$ and $75(21.2 \%)$ were classified as obese (BMI $\geq 30)$. Of women defined as obese, $41(54.7 \%)$ were classified as obesity class I (BMI $30.0-34.9 \mathrm{~kg} / \mathrm{m}^{2}$ ), 
Table 1 Accuracy of estimation of BMI by women in each weight category

\begin{tabular}{lllllll}
\hline & \multicolumn{2}{l}{ Perceived BMI category } & & \\
\cline { 3 - 5 } & & Underweight & Normal weight & Overweight & Very overweight \\
\hline Actual BMl category & Normal & $8(4.5)$ & $155(86.6)$ & $16(8.9)$ & $0(0)$ \\
& Overweight & $0(0)$ & $34(34.3)$ & $65(65.7)$ & $0(0)$ \\
& Obese & $0(0)$ & $5(6.7)$ & $52(69.3)$ & $18(24.0)$ \\
\hline
\end{tabular}

Data is $\mathrm{n}(\%), \mathrm{p}<0.05$

Normal weight was defined as BMI $20-24.9 \mathrm{~kg} / \mathrm{m}^{2}$, overweight BMI $25-29.9 \mathrm{~kg} / \mathrm{m}^{2}$, obese BMI $\geq 30$.

20 (26.7\%) were classified as obesity class II (BMI 35.0$\left.39.9 \mathrm{~kg} / \mathrm{m}^{2}\right)$ and $14(18.7 \%)$ were classified as morbidly obese $\left(B M I \geq 40.0 \mathrm{~kg} / \mathrm{m}^{2}\right)$. The maximum BMI was $60 \mathrm{~kg} / \mathrm{m}^{2} .171(48.4 \%)$ of the women were nulliparous, $182(51.6 \%)$ had a tertiary education, $312(88.4 \%)$ had seen a doctor or midwife during the pregnancy and 25 (7.1\%) of had been diagnosed with gestational diabetes, but 81 women had not yet been tested. The median and interquartile age was 31.1(28-35) years and median gestation at the time of the interview was $28(20-36)$ weeks. Hospital birth statistics from the hospital data base the same year indicate that the convenience sample was similar to the general population regarding parity (46.5\% nulliparous), maternal age 31.0 (28-35) years, and BMI (51.1\% normal weight, $28.9 \%$ overweight and $20.3 \%$ obese).

Women's perceptions of their own weight are presented in Table 1 . The majority $(86.6 \%)$ of normal weight women identified themselves as such, however nearly one in 10 considered themselves overweight. While around two-thirds of women accurately identified they were overweight, the remainder considered themselves to be normal weight. The majority of obese women considered themselves to be overweight and these women were the most likely to underestimate their own BMI category, with only $24 \%$ identifying themselves as very overweight.

As shown in Table 2, misperceptions regarding appropriate weight gain in pregnancy were commonplace, with overweight or obese women being least accurate at estimating appropriate GWG. Those women who underestimated their own weight were more likely to overestimate optimal weight gain in pregnancy.

Ninety-four per cent of women believed that excess GWG or obesity would be associated with increased pregnancy complications, but their knowledge of the specific nature of these risks was poor. $27.8 \%$ of women identified preeclampsia or blood pressure problems, 51\% identified gestational diabetes and $14.4 \%$ suggested postpartum weight retention (data not presented in tables). $71 \%$ of women suggested concerns such as back pain or difficulty moving. Less than $5 \%$ of women suggested caesarean section, operative delivery, preterm birth or postterm delivery as being related to maternal BMI or GWG. 72.8\% believed that there could be neonatal complications from obesity or GWG and $18.4 \%$ suggested macrosomia. Less than $5 \%$ of women suggested any other neonatal complications including hypoglycaemia, jaundice special care nursery admission or increased perinatal mortality.

Table 2 Accuracy of estimation of recommended weight gain in pregnancy by women in each BMI category and perceived weight category

\begin{tabular}{|c|c|c|c|c|c|}
\hline & \multicolumn{4}{|c|}{ Estimation of recommended weight gain } & \\
\hline & Underestimate & Correct & Overestimate & $\begin{array}{l}\text { Unable to } \\
\text { estimate }\end{array}$ & \\
\hline \multicolumn{6}{|c|}{ Women classified according to BMI category } \\
\hline Normal $n=179$ & $56(31.3)$ & $\begin{array}{l}104 \\
(58.1)\end{array}$ & $13(7.3)$ & $6(3.4)$ & \multirow[t]{3}{*}{$\begin{array}{l}p= \\
0.001\end{array}$} \\
\hline Overweight $n=99$ & $7(7.1)$ & $47(47.5)$ & $40(40.4)$ & $5(5.1)$ & \\
\hline Obese $n=75$ & 10(13.3) & $16(21.3)$ & $48(64.0)$ & $1(1.3)$ & \\
\hline \multicolumn{6}{|c|}{$\begin{array}{l}\text { Woman classified according to difference between actual and perceived } \\
\text { weight category }\end{array}$} \\
\hline Underestimate $n=98$ & $10(10.2)$ & 23(23.5) & $61(62.2)$ & $4(4.1)$ & \multirow{2}{*}{$\begin{array}{l}p= \\
0.01\end{array}$} \\
\hline Correct $n=239$ & $60(25.1)$ & $\begin{array}{l}132 \\
(55.2)\end{array}$ & $39(16.3)$ & $8(3.3)$ & \\
\hline Overestimate $n=16$ & $3(18.8)$ & $12(75.0)$ & $1(6.3)$ & $0(.0)$ & \\
\hline
\end{tabular}


Table 3 Women's beliefs about safe and effective management of weight gain in pregnancy

\begin{tabular}{lll}
\hline & $\begin{array}{l}\text { Expert } \\
\text { opinion }\end{array}$ & $\begin{array}{l}\text { Number (\%) of participants } \\
\text { answering correctly }\end{array}$ \\
\hline $\begin{array}{l}\text { Dietary behavior } \\
\text { Skip meals }\end{array}$ & No & $348(98.6)$ \\
$\begin{array}{l}\text { Eat for two } \\
\text { Remove fat from meat }\end{array}$ & Yes & $309(87.5)$ \\
$\begin{array}{l}\text { Finish everything on } \\
\text { your plate }\end{array}$ & No & $309(88.1)$ \\
$\begin{array}{l}\text { Stop eating after eight } \\
\text { pm at night }\end{array}$ & No & $222(62.9)$ \\
$\begin{array}{l}\text { Dietary approaches } \\
\text { Choose low fat milk and } \\
\text { dairy products }\end{array}$ & Yes & $233(66.0)$ \\
$\begin{array}{l}\text { Eat less cakes and } \\
\text { chocolate }\end{array}$ & Yes & $339(96.0)$ \\
$\begin{array}{l}\text { Eat a gluten free diet } \\
\text { Drink less soft drink }\end{array}$ & No & $278(78.8)$ \\
$\begin{array}{l}\text { Drink more fruit juice } \\
\text { Eat plenty of fruit and } \\
\text { vegetables }\end{array}$ & No & $350(99.2)$ \\
$\begin{array}{l}\text { Eat less take away foods } \\
\text { Eat less fried foods }\end{array}$ & Yes & $353(67.7)$ \\
$\begin{array}{l}\text { Eat an Atkins/low } \\
\text { carbohydrate diet }\end{array}$ & No & $352(90)$ \\
$\begin{array}{l}\text { Drink soy milk instead of } \\
\text { cows milk }\end{array}$ & No & $298(84.4)$ \\
$\begin{array}{l}\text { Eat an organic diet } \\
\text { Exercise }\end{array}$ & No & $181(51.2)$ \\
$\begin{array}{l}\text { Exercise } 3 \text { or more times } \\
\text { each week }\end{array}$ & Yes & $332(94.1)$ \\
$\begin{array}{l}\text { Avoid exercise } \\
\text { Tota } 353 \text { women }\end{array}$ & $352(99.7)$ \\
\hline
\end{tabular}

Total 353 women.

The Institute of Medicine (IOM) guidelines for weight gain in pregnancy [12] and the Australian guide to healthy eating [13] formed the basis of "expert opinion".

Study participants were also found to hold many incorrect beliefs about safe weight management in pregnancy, more than one third of women believed that eating an organic diet, drinking more fruit juice, not eating after $8 \mathrm{pm}$ or choosing full fat dairy products were safe ways to manage weight gain in pregnancy (Table 3 ). No association was demonstrated between women's BMI category, parity, care provider, age or educational status and their level of knowledge of maternal or neonatal complications or beliefs about diet in pregnancy (data not shown).

\section{Discussion}

In this convenience sample of obstetric patients from a large metropolitan hospital we show frequent misclassification of BMI. Women predominantly underestimated their degree of overweight or obesity and overweight and obese pregnant women were more prone to inaccurate self-classification compared with normal weight women. Twenty-four per cent of obese pregnant women accurately classified their BMI in the current study which is similar to rates of $10 \%$ in Canada [14], $16 \%$ in Brisbane, Australia [15] and 30\% in Canberra, Australia [16]. By comparison $87 \%$ of normal weight women in our sample were accurate in classifying their BMI, a finding similar to $89 \%$ in Brisbane [15] and 94\% recorded in Canada [14]. BMI classification is similarly inaccurate in some studies of non-pregnant overweight and obese women [17] where only $16 \%$ of obese and $31 \%$ of overweight women correctly classified their BMI by matching themselves against standard silhouettes. Weight perception is generally more accurate in women than men $[18,19]$. It is possible that the increasing prevalence of obesity is changing the community's perception of what is "normal".

Previous studies have asked pregnant women what they actually eat. To our knowledge, our study is the first to characterize pregnant women's beliefs about appropriate dietary approaches to achieve safe and effective management of weight gain in pregnancy, demonstrating that many pregnant women's ideas of appropriate diet in pregnancy diverge from expert opinion. The diet questions were intentionally very simple. This was for 2 reasons, firstly to give participants confidence in answering questions about a sensitive topic, weight gain and diet, and to demonstrate the low level of knowledge for even simple information. Midwives and obstetric doctors should not assume that pregnant women are using safe strategies to avoid excess GWG. Inaccurate or unsafe ideas about ways to contain gestational weight may contribute to the increasing frequency of excess GWG. Avoiding excess GWG is important for women in the long term [20], is associated with better perinatal outcome [4,21-23] and appears to reduce inter-generational transmission of obesity [24] but is not usual. More than half of overweight pregnant women gain in excess of that recommended by the IOM $[20,25,26]$ and this trend is increasing rather than abating $[27,28]$.

We have also demonstrated that pregnant women have a low awareness of the perinatal complications associated with excess maternal weight $[14,29]$. Women may be more aware of personal long term health risks rather than of perinatal risks associated with obesity [14]. Better awareness of these complications may provide a motivating factor for women to maintain appropriate GWG in order to improve outcomes for their baby.

The strengths of this study include a large sample size, and demographic details which are similar to state data [30] suggesting that despite sampling at a tertiary, Australian, urban maternity hospital the findings may 
be generalisable to the wider population. In contrast, Gaudet's Canadian study overrepresented older, nulliparous, tertiary educated pregnant women compared with population data [14]. A single researcher performed all of the interviews to exclude interobserver variation. An interview process may increase participation compared with written surveys, especially for women less confident in their written language abilities.

A weakness in our study was that we did not assess ethnicity and therefore cannot comment on any cultural or ethnic differences in knowledge or perception of obesity or GWG. Knowledge of prepregnancy weight may have also been useful to understand how weight gain in pregnancy was impacted by women's understanding of GWG targets. We also used self reported height and weight but self-report of height and weight in pregnancy has been found to have a high correlation with measured height and weight in a large Australian sample [11]. A convenience sample was used, which increased study numbers, however the demographics of the sample closely matched that of the hospital population as described in the results above.

Other reasons why many women, especially those commencing pregnancy overweight or obese, find it difficult to contain GWG within recommended limits could include:

misperception and knowledge gaps for pregnant women and/or maternity caregivers [31-33], professional lack of confidence in being able to help overweight and obese people improve their weight $[33,34]$, inequitable distribution of overweight and obesity such that socioeconomic deprivation commonly co-exists and this impedes access to good quality food and safe exercise [35].

Ours is the first Australian survey to assess women's knowledge of GWG goals in an era and setting where serial weighing in pregnancy is not supported by local guidelines [36]. Canadian survey respondents had a more accurate understanding of recommended GWG in their setting where serial weighing remains part of routine antenatal care [14]. A previous randomized controlled trial (RCT) from our institution supports serial self-weighing, particularly for overweight women, to achieve specific GWG goals [37]. This is being extended in a new RCT which includes obese as well as overweight women and is powered to demonstrate a clinically meaningful degree of improvement in obstetric complications and in which psychological benefit or detriment of serial weighing will also be addressed (Australian New Zealand Clinical Trial Registry number ACTRN12611000881932).

Regarding research implications, we did not explore sources of error leading to inaccurate self-classification of BMI, inappropriate GWG goals, inaccurate knowledge of obesity-related perinatal complications or safe methods to contain GWG. The Canadian survey found that maternity professionals were pregnant women's most common source of information about weight in pregnancy but that $59.8 \%$ of women obtained information from the internet [14]. In other research obstetric care providers have been shown to lack skills and confidence in counselling women around weight management $[10,38]$. Future research into professional and lay sources of information, including mobile telephone and webbased social networking can help plan novel behavioural programmes, especially for women entering pregnancy obese or overweight. This is particularly important since a systematic review of studies using behavioral advice, diet and physical activity shows only inconsistent success in limiting GWG [39]. Outside of pregnancy, commercial weight loss programmes may be more successful than health professional led programmes [34].

\section{Conclusion}

Obesity and excessive GWG are increasing problems in the obstetric population. Lack of knowledge of personal BMI, GWG targets limits and appropriate weight management strategies may limit the ability of women to address these issues successfully during their pregnancy.

\section{Additional file}

Additional file 1: Questionnaire - Women's knowledge of pregnancy weight gain.

\section{Abbreviations}

BMI: Body mass index; IOM: Institute of medicine; GWG: Gestational weight gain; GDM: Gestational diabetes mellitus; RCT: Randomized controlled trial.

\section{Competing interest}

The authors declare they have no competing of interest.

\section{Authors' contributions}

AS and $\mathrm{EH}$ designed research; EH conducted research; AS analyzed data; AS, EM and KC wrote the paper; AS had primary responsibility for final content. All authors read and approved the final manuscript. The authors would like to acknowledge the assistance of Dr Carolyn J. Wicks with data entry and collation. All authors read and approved the final manuscript.

\section{Author details}

${ }^{1}$ Department of Obstetrics and Gynaecology, University of Melbourne, Perinatal Centre, 3rd Floor, Mercy Hospital for Women, 163 Studley Road, Heidelberg, Victoria, 3078, Australia. ${ }^{2}$ Centre for Physical Activity and Nutrition Research, School of Exercise and Nutrition Sciences, Deakin University (KC), Geelong, Melbourne, Australia.

Received: 16 May 2013 Accepted: 1 July 2013

Published: 18 July 2013

\section{References}

1. World Health Organization: Obesity: preventing and managing the global epidemic. Report of a WHO consultation (WHO Technical Report Series 894). Geneva Switzerland; 1999.

2. Dodd JM, Grivell RM, Nguyen AM, Chan A, Robinson JS: Maternal and perinatal health outcomes by body mass index category. Aust N Z J Obstet Gynaecol 2011, 51:136-140. 
3. Flegal KM, Carroll MD, Kit BK, Ogden CL: Prevalence of obesity and trends in the distribution of body mass index among US adults, 1999-2010. JAMA 2012, 307:491-497.

4. Cedergren M: Effects of gestational weight gain and body mass index on obstetric outcome in Sweden. Int J Gynaecol Obstet 2006, 93:269-274.

5. Raatikainen K, Heiskanen N, Heinonen S: Transition from overweight to obesity worsens pregnancy outcome in a BMI-dependent manner. Obesity (Silver Spring) 2006, 14:165-171.

6. Fraser A, Tilling K, Macdonald-Wallis C, Sattar N, Brion MJ, Benfield L, Ness A, Deanfield J, Hingorani A, Nelson SM, et al: Association of maternal weight gain in pregnancy with offspring obesity and metabolic and vascular traits in childhood. Circulation 2010, 121:2557-2564

7. Rode L, Kjaergaard H, Ottesen B, Damm P, Hegaard HK: Association between gestational weight gain according to body mass index and postpartum weight in a large cohort of Danish women. Matern Child Health J 2012, 16:406-413.

8. Flenady V, Middleton P, Smith GC, Duke W, Erwich JJ, Khong TY, Neilson J, Ezzati M, Koopmans L, Ellwood D, et al: Stillbirths: the way forward in high-income countries. Lancet 2011, 377:1703-1717.

9. Callaway LK, O'Callaghan MJ, Mclntyre HD: Barriers to addressing overweight and obesity before conception. Med J Aust 2009, 191:425-428.

10. Herring SJ, Oken E, Haines J, Rich-Edwards JW, Rifas-Shiman SL, Kleinman SC DK, Gillman MW: Misperceived pre-pregnancy body weight status predicts excessive gestational weight gain: findings from a US cohort study. BMC Pregn Childbirth 2008, 8:54.

11. Mamun AA, Lawlor DA, O'Callaghan MJ, Williams GM, Najman JM: Family and early life factors associated with changes in overweight status between ages 5 and 14 years: findings from the mater university study of pregnancy and its outcomes. Int J Obes (Lond) 2005, 29:475-482.

12. Weight gain during pregnancy Reexamining the guidelines. In Committee to Reexamine IOM Pregnancy Weight Guidelines Food and Nutrition Board, Board on Children, Youth, and Families Institute of medicine and national research council of the national academies. Edited by Rasmussen KM, Yaktine AL. Washington, DC: The national academies press; 2009.

13. Kellett E, Smith A, Schmerlaib Y: The Australian guide to healthy eating Department of Health and Ageing. In Funded by the Australian Government Department Of Health and Ageing. Edited by Foundation CsHD ed. Canberra: Prepared by the Children's Health Development Foundation, South Australia, and Deakin University, Victoria; 1998.

14. Gaudet LM, Gruslin A, Magee LA: Weight in pregnancy and its implications: what women report. J Obstet Gynaecol Can 2011, 33:227-234.

15. Callaway LK, Prins JB, Chang AM, Mclntyre HD: The prevalence and impact of overweight and obesity in an Australian obstetric population. Med J Aust 2006, 184:56-59.

16. Thompson MW, Nassar N, Robertson M, Shand AW: Pregnant women's knowledge of obesity and ideal weight gain in pregnancy, and health behaviours of pregnant women and their partners. Aust N Z J Obstet Gynaecol 2011, 51:460-463.

17. Potti S, Milli M, Jeronis S, Gaughan JP, Rose M: Self-perceptions of body size in women at an inner-city family-planning clinic. Am J Obstet Gynecol 2009, 200:e65-e68.

18. Yaemsiri S, Slining MM, Agarwal SK: Perceived weight status, overweight diagnosis, and weight control among US adults: the NHANES 2003-2008 Study. Int J Obes (Lond) 2011, 35:1063-1070.

19. Donath SM: Who's overweight? Comparison of the medical definition and community views. Med J Aust 2000, 172:375-377.

20. Chu SY, Callaghan WM, Bish CL, D'Angelo D: Gestational weight gain by body mass index among US women delivering live births, 2004-2005: fueling future obesity. Am J Obstet Gynecol 2009, 200(271):e271-e277.

21. Cedergren Ml: Optimal gestational weight gain for body mass index categories. Obstet Gynecol 2007, 110:759-764.

22. Kiel DW, Dodson EA, Artal R, Boehmer TK, Leet TL: Gestational weight gain and pregnancy outcomes in obese women: how much is enough? Obstet Gynecol 2007, 110:752-758

23. Edwards LE, Hellerstedt WL, Alton IR, Story M, Himes JH: Pregnancy complications and birth outcomes in obese and normal-weight women: effects of gestational weight change. Obstet Gynecol 1996, 87:389-394.

24. Beyerlein A, Nehring I, Rzehak P, Heinrich J, Muller MJ, Plachta-Danielzik S, Wabitsch M, Weck M, Brenner H, Rothenbacher D, von Kries R: Gestational weight gain and body mass index in children: results from three german cohort studies. PLoS One 2012, 7:e33205.
25. Keppel KG, Taffel SM: Pregnancy-related weight gain and retention: implications of the 1990 Institute of Medicine guidelines. Am J Public Health 1993, 83:1100-1103

26. Carmichael S, Abrams B, Selvin S: The pattern of maternal weight gain in women with good pregnancy outcomes. Am J Public Health 1997, 87:1984-1988

27. Martin JA, Hamilton BE, Sutton PD, Ventura SJ, Mathews TJ, Kirmeyer S, Osterman MJ: Births: final data for 2007. Natl Vital Stat Rep 2010, 58:1-85.

28. Ventura SJ, Martin JA, Curtin SC, Mathews TJ: Births: final data for 1997. Natl Vital Stat Rep 1999, 47:1-96.

29. Nitert MD, Foxcroft KF, Lust K, Fagermo N, Lawlor DA, O'Callaghan M, Mclntyre HD, Callaway LK: Overweight and obesity knowledge prior to pregnancy: a survey study. BMC Pregn Childbirth 2011, 11:96.

30. Consultative Council on Obstetric and Paediatric Mortality and Morbidity: Births in victoria 2007 and 2008. In hospital \& health service performance division (quality SPEB ed. Melbourne Victoria Australia: State of Victoria, Department of Health; 2011.

31. Stotland NE, Haas JS, Brawarsky P, Jackson RA, Fuentes-Afflick E, Escobar GJ: Body mass index, provider advice, and target gestational weight gain. Obstet Gynecol 2005, 105:633-638

32. Groth SW, Kearney MH: Diverse women's beliefs about weight gain in pregnancy. J Midwifery Womens Health 2009, 54:452-457.

33. Herring SJ, Platek DN, Elliott P, Riley LE, Stuebe AM, Oken E: Addressing obesity in pregnancy: what do obstetric providers recommend? J Womens Health (Larchmt) 2010, 19:65-70.

34. Jolly K, Lewis A, Beach J, Denley J, Adab P, Deeks JJ, Daley A, Aveyard P: Comparison of range of commercial or primary care led weight reduction programmes with minimal intervention control for weight loss in obesity: lighten Up randomised controlled trial. BMJ 2011, 343:d6500.

35. Fowles ER, Fowles SL: Healthy eating during pregnancy: determinants and supportive strategies. J Commun Health Nurs 2008, 25:138-152.

36. Guidelines: low risk pregnancy. http://3centres.com.au/guidelines/low-riskpregnancy/routine-weighing-at-antenatal-visits.

37. Jeffries K, Shub A, Walker SP, Hiscock R, Permezel M: Reducing excessive weight gain in pregnancy: a randomised controlled trial. Med J Aust 2009, 191:429-433.

38. van der Pligt P, Campbell K, Willcox J, Opie J, Denney-Wilson E: Opportunities for primary and secondary prevention of excess gestational weight gain: general practitioners' perspectives. BMC Fam Pract 2011, 12:124

39. Skouteris H, Hartley-Clark L, McCabe M, Milgrom J, Kent B, Herring SJ, Gale J: Preventing excessive gestational weight gain: a systematic review of interventions. Obes Rev 2010, 11:757-768.

\section{doi:10.1186/1756-0500-6-278}

Cite this article as: Shub et al:: Pregnant women's knowledge of weight, weight gain, complications of obesity and weight management strategies in pregnancy. BMC Research Notes 2013 6:278.

\section{Submit your next manuscript to BioMed Central and take full advantage of:}

- Convenient online submission

- Thorough peer review

- No space constraints or color figure charges

- Immediate publication on acceptance

- Inclusion in PubMed, CAS, Scopus and Google Scholar

- Research which is freely available for redistribution 